\title{
Age and Gender Based Differences in Self-Assessed Reflection- in-Learning Scale
}

\author{
Nabiha Farasat Khan ${ }^{1}$ \\ Muammad Saeed ${ }^{2}$ \\ Rahila Yasmin ${ }^{3}$ \\ Arshad Kamal Butt ${ }^{4}$ \\ Ayyaz Ali Khan ${ }^{5}$
}

\author{
BDS, M.Phil, MPHE \\ BDS \\ PhD Scholar \\ MBBS, FCPS (Gastro, Medicine) MPHE \\ BDS, MSc, PhD
}

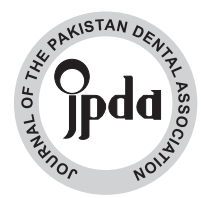

\begin{abstract}
ABSTRAT: Reflection heighten students' self-directed and life-long leaning. Gender difference probably represents significant sources of variation in learning behavior which should be detected and identified by medical educationists. This study was accomplished to "compare difference in Reflection-in-Learning Score between the gender and age of dental students in Bolan Medical College, Quetta."

METHODOLOGY: An observational quantitative Census was carried out in all professional year dental students ( $\mathrm{n}=85)$ of Bolan Medical College, Quetta. Data was collected during the period of 6 months (December, 2015 to May, 2016). A proforma was distributed to the participants under the supervision of principal investigator in lecture hall, time allotted to complete questionnaire was half hour; RLS was then collected, data was coded and entered in Special Package for Social Sciences version 20 for analysis. Frequency, percentage, means, median and standard deviation were computed for each RLS statement. Shapiro Wilk test was utilized to check normality of data whereas ANOVA scrutinized difference between RLS score and gender. P-value $<0.05$ was considered significant.

RESULTS: Out of 85 study participants $21(24.8 \%)$ were from 1st year, $16(18.8 \%)$ from 2nd year, $20(23.5 \%)$ from 3rd year and $28(32.9 \%)$ from 4th year. Females participants were dominant $(72.9 \%)$ and acquire statistically significant RLS score. ( $\mathrm{P}=<0.001)$ Majority of the samples belong to 20-22 years age group, $14(16.5 \%)$ were more than 23 years whereas $6(7.1 \%)$ were below 20 years presenting no statistically significant age difference. ( $\mathrm{P}=0.413)$

CONCLUSION: Females participants were more reflective, whereas age doesn't matter in RLS score.

KEY WORDS: Undergraduate Dental Students, differences, Gender, Age, Reflection-in-Learning Scale.

HOW TO CITE: Khan NF, Saeed M, Yasmin R, Butt AK, Khan AA. Age and gender based differences in self-assessed reflection-in-learning scale. J Pak Dent Assoc 2018;27(3):133-39.

DOI: https://doi.org/10.25301/JPDA.273.133

Received: 03 February 2017, Accepted: 06 March 2018
\end{abstract}

\section{INTRODUCTION}

$\mathrm{T}$ he students of Asian origin have enhanced learning skills due to their ability to combine memorization and understanding. ${ }^{1,2,3}$ Education is a female dominant field possibly because of their devotion, keenness and single mindedness. ${ }^{4}$ Additionally competency of females at acquiring new learning strategies makes them more

1. Associate Professor \& Head of Oral Pathology Dental Section, Bolan Medical College, Quetta.

2. Senior Demonstrator, Department of Prosthodontics, Bolan Medical College, Quetta. 3. Associate Dean, Riphah Academy of Research and Education Riphah, Islamabad.

4. Professor, Department of Medicine, Shakih Zayed Federal Postgraduate, Medical Institute, Lahore.

5. Diector, Department of Institute, Shakih Zayed Federal Postgraduate, Medical Institute, Lahore.

Corresponding author: "Dr. Nabiha Farasat Khan" < nabihasaeed@hotmail.com > valuable and prominent. ${ }^{5}$

Reflection is a new and crucial component of medical education which enhances life-long learning. ${ }^{6,7}$ Reflective students are capable to mount Miller's pyramid from cognition towards interpretation which strengthens their self-regulation, self-efficacy and builds them self-directed and life-long learners. Self-reflection accomplishes students to determine and analyze gaps in acquisition by jurisdiction of their emotions and to strengthen their performance, demonstrating positive consequences on their attitude. ${ }^{8,9,10,11}$ Reflective students get exquisite and marvelous results in their academics. ${ }^{12,13,14}$

Self-assessed, 14-item, Reflection-in-Learning Scale is a self-reported questionnaire that describes the views of student's self-regulated learning. It has been implemented, 
and its effectiveness is proved in medicine and dentistry. Amal M (2010) from UK executed RLS on dental students of King Abdul Aziz University of Dentistry and concluded that there was a statistically significant association between reflective students and academic performance $(\mathrm{P}<0.001){ }^{6}$ Whereas Sobral DT noticed that $81 \%(n=83 / 103)$ of his study participants were reflective learners, exhibiting diagnostic thinking abilities. ${ }^{12}$ However controversy existed in the results finalized by an Irish investigator, Chalmers P (2011), who distinguished no progress in academic performance of 56 study participants from final year medicine..$^{15}$ Devi V, an Indian researcher, pointed out the level of reflection, but she didn't work on gender and age difference in RLS. ${ }^{16}$

Reflection-in-Learning Scale is acceptable to manipulate in the discipline of medicine and dentistry. Researchers scrutinize RLS on nurses also. ${ }^{17,18}$ Although foreign countries have carried out considerable efforts to assess reflective level of medical/dental students, but still no work has been accomplished to compare RLS score between male and female students. ${ }^{12,14,15,16,17,19,20,21}$ Gender difference represents significant sources of variation in learning behavior of medical/dental students which should be detected and identified by medical educationists. ${ }^{22,23}$

Although, research has been carried out and reflective level assessed previously in Pakistan, but the gender difference for RLS has yet not been checked. ${ }^{24,25,26} \mathrm{We}$ utilized this questionnaire in the current study with an aim to compare (if any) difference of RLS exists between male and female students in a government medical college in Quetta.

The rationale of applying RLS in the current study is its effectiveness in the assessment and monitoring of student learning; moreover, it also furnishes the educational feedback of the students and helps recognize requisite of learning processes which assists in better understanding of learning material. ${ }^{16}$

\section{METHODOLOGY}

It was a questionnaire based survey carried out in Bolan Medical College (BMC), Quetta, Balochistan, Pakistan on $\mathrm{n}=85$ BDS students of 1st, 2nd, 3rd and 4th year. Ethical approval from administration of University of Lahore; IRB No: 03/1609, dated 26.01.2016 and Principal Bolan Medical College (BMC), Quetta; Letter No.Admin/BMC/2016/2416/18 was taken. Data was collected during the period of December, 2015 to March, 2016. There were 95 dental student; 6 were absent whereas 4 students refused to participate in the study. Thus, a total of $n=85$ students were recruited for the study.
A demonstrator of dental section BMC distributed selfassessed questionnaire 14-item Reflection-in-Learning Scale (RLS) among the participants after filling the consent form. Study was explained and they were reassured about the confidentiality of their personal information. Time allotted for filling the questionnaire was half hour after that RLS was collected. The data was entered and analyzed using SPSS (Statistical Package for Social Sciences) version 20. Frequency and percentages were given for each statement of RLS. Mean, median and standard deviation were also given for each statement. Shapiro Wilk test was used to check the normality of data. Due to the availability of data, its normal distribution and possibility to compare, ANOVA test was utilized to examine the mean difference in RLS score among male and female participants. A p-value $<$ 0.05 was considered as significant.

RLS is formulated by a Brazilian researcher Sobral DT in $2000 .{ }^{12}$ It has proved constructive validity and good internal consistency. RLS is presented as Annexure 1.

To confirm the acceptability of questionnaire in public sector medical college, the questionnaire was applied in 20 students of 3rd year BDS to construct reliability and cognitive understanding. All of these students understand the questionnaire and its language easily; they fill it comfortably.

Students were recommended high mastery of reflective level when they encircle on Likert scale 7, competent reflective when participants encompassing option 6 , they display basic/acceptable reflective when tick on scale 5, while exhibit minimally acceptable/progressing reflective degree of reflection when they encircle on scale 4, crude/emerging on scale 3 and inappropriate on 1 and 2 of Likert scale. ${ }^{27}$ For statistical purposes and its ease, the final score was further divided into 4 sub-scales representing the self-assessment question, participants scoring 14-34 were designated as limited reflective level, subjects having 35-55 score presented partial reflective level, as well as students demonstrated 56-76 score have ample level of reflection and students have maximum level of reflection when they score $77-98 .^{6}$

\section{RESULTS}

Total strength of BDS students in Bolan Medical College Quetta was 95. Students gave a good response (89.47, approximately $90 \%$ ) as only 6 of them refused to take part in the study while 4 were absent at the time of data collection. Out of $85 / 95$ dental students, majority $(72.9 \%)$ were females. Only $16.5 \%$ (14) participants were above the age of 23 years, whereas $7.1 \%$ were below 20 years, $76.5 \%$ (65) participants belonged to the $20-22$ age group. 
Comparison of Reflective-In-Learning Scale Score between Genders:

Independent sample t-test was used to compare the RLS score between male and female students. Mean RLS score of female students was significantly higher as compared to male students. Table 1 presented RLS score between genders.
Table 1: Comparison of Reflective-In-Learning Scale score between Genders

\begin{tabular}{|c|l|l|r|r|r|}
\hline \multirow{2}{*}{ Gender } & \multicolumn{5}{|c|}{ Reflective-In-Learning Scale } \\
\cline { 2 - 6 } & N & Mean \pm SD & Minimum & Maximum & p-value \\
\hline Male & 23 & $77.26 \pm 3.99$ & 70.0 & 84.0 & $<0.001$ \\
\hline Female & 62 & $83.09 \pm 4.24$ & 74.0 & 91.0 & \\
\hline
\end{tabular}

*Independent t-test

\begin{tabular}{|c|c|c|c|c|c|c|}
\hline \multicolumn{6}{|c|}{ Group Statistics } & \multirow[b]{2}{*}{ p-value } \\
\hline & Gender & $\mathbf{N}$ & Mean & Std. Deviation & $\begin{array}{c}\text { Std. Error } \\
\text { Mean }\end{array}$ & \\
\hline \multirow{2}{*}{ Carefully plan task } & male & 23 & 5.74 & 0.62 & 0.13 & \multirow{2}{*}{$0.010^{*}$} \\
\hline & female & 62 & 6.21 & 0.77 & 0.10 & \\
\hline \multirow{2}{*}{ Disscusion with colleagues } & male & 23 & 5.52 & 0.73 & 0.15 & \multirow{2}{*}{$<0.001^{*}$} \\
\hline & female & 62 & 6.21 & 0.77 & 0.10 & \\
\hline \multirow{2}{*}{ Review study } & male & 23 & 5.74 & 0.62 & 0.13 & \multirow{2}{*}{$0.005^{*}$} \\
\hline & female & 62 & 6.23 & 0.82 & 0.10 & \\
\hline \multirow{2}{*}{ Integration } & male & 23 & 5.65 & 0.49 & 0.10 & \multirow{2}{*}{0.178} \\
\hline & female & 62 & 5.92 & 0.89 & 0.11 & \\
\hline \multirow{2}{*}{ Process mentally } & male & 23 & 5.61 & 0.66 & 0.14 & \multirow{2}{*}{0.128} \\
\hline & female & 62 & 5.87 & 0.71 & 0.09 & \\
\hline \multirow{2}{*}{ Aware of learning task } & male & 23 & 5.83 & 0.83 & 0.17 & \multirow{2}{*}{0.137} \\
\hline & female & 62 & 6.15 & 0.88 & 0.11 & \\
\hline \multirow{2}{*}{ Develop interrelation } & male & 23 & 5.87 & 1.10 & 0.23 & \multirow{2}{*}{$0.018^{*}$} \\
\hline & female & 62 & 6.50 & 0.84 & 0.11 & \\
\hline \multirow[b]{2}{*}{ Ponder for learning } & male & 23 & 5.65 & 0.83 & 0.17 & \multirow[b]{2}{*}{$0.014^{*}$} \\
\hline & female & 62 & 6.13 & 0.76 & 0.10 & \\
\hline \multirow{2}{*}{ Change myself for study } & male & 23 & 6.09 & 0.73 & 0.15 & \multirow{2}{*}{0.492} \\
\hline & female & 62 & 6.21 & 0.73 & 0.09 & \\
\hline \multirow{2}{*}{ Reflection on study } & male & 23 & 5.83 & 0.65 & 0.14 & \multirow{2}{*}{0.062} \\
\hline & female & 62 & 6.16 & 0.75 & 0.10 & \\
\hline \multirow{2}{*}{ Make summary } & male & 23 & 5.83 & 0.72 & 0.15 & \multirow{2}{*}{$0.026^{*}$} \\
\hline & female & 62 & 6.24 & 0.76 & 0.10 & \\
\hline \multirow{2}{*}{ Use capacity to reflect } & male & 23 & 5.61 & 0.66 & 0.14 & \multirow{2}{*}{$0.001^{*}$} \\
\hline & female & 62 & 6.23 & 0.73 & 0.09 & \\
\hline \multirow{2}{*}{ Remove negativity } & male & 23 & 5.91 & 0.60 & 0.12 & \multirow{2}{*}{$0.018^{*}$} \\
\hline & female & 62 & 6.31 & 0.80 & 0.10 & \\
\hline \multirow{2}{*}{ Self assess } & male & 23 & 5.87 & 0.69 & 0.14 & \\
\hline & female & 62 & 6.45 & 0.72 & 0.09 & $0.001^{*}$ \\
\hline Reflective-In-Learning Scale & male & 23 & 77.26 & 3.99 & 0.83 & \\
\hline score & female & 62 & 83.10 & 4.25 & 0.54 & $<0.001^{*}$ \\
\hline & male & 23 & 5.52 & 0.29 & 0.06 & $<0001 *$ \\
\hline Mean score & female & 62 & 5.94 & 0.30 & 0.04 & $<0.001^{*}$ \\
\hline
\end{tabular}

$*$ Significant results 


\section{Comparison of Reflective-in-Learning Scale among Age groups:}

Analysis of variance (ANOVA) test was performed to compare the RLS score among the various age groups. One way ANOVA test revealed that there was no statistically significant difference in mean RLS score among them. Table 2 demonstrated RLS score among age groups.

Table 1: Comparison of Reflective-In-Learning Scale score between Genders

\begin{tabular}{|c|r|r|r|r|}
\hline \multirow{2}{*}{$\begin{array}{c}\text { Age of } \\
\text { Participants }\end{array}$} & \multicolumn{4}{|c|}{ Reflective-In-Learning Scale } \\
\cline { 2 - 4 } & \multicolumn{1}{|c|}{ Mean $\mathbf{\text { SD }}$} & Minimum & \multicolumn{1}{|c|}{ Maximum } & p-value \\
\hline $\mathbf{2 0}$ years & $79.17 \pm 6.08$ & 73.0 & 85.0 & \\
\hline $\mathbf{2 0 - 2 2}$ year & $81.55 \pm 5.00$ & 70.0 & 91.0 & \multirow{2}{*}{0.413} \\
\hline$>23$ years & $82.36 \pm 3.85$ & 75.0 & 90.0 & \\
\hline
\end{tabular}

*One way ANOVA test

\section{DISCUSSION}

Today, women are almost proving to be in the lead in every walk of life and every profession due to their sense of responsibility, constant hard work and great determination. This is true in medical education and field of dentistry as well as most of the study results displayed female dominance. In Pakistan, $65 \%$ of the medical students admission are females and their number is rising yearly. ${ }^{28}$ Studies that measure Reflection-in-Learning Scale of medical students in different countries including Saudi Arabia, London, U.K, Brazil, Netherland, Ireland, India, Australia, UK, Taiwan, Sweden, US and Estonia also demonstrate female dominance in the medicine. ${ }^{4,6,7,12,14,15,16,19,20,21,29,30}$

In Balochistan, which is primarily a male predominating society, it is surprising to hear that females are dominating in dentistry. The percentage of female literacy is lower in Balochistan as compared to the other parts of the country due to a bundle of varying factors including remote educational institutes, financial constraints, social problems and cultural barriers. ${ }^{31}$ However, as girls are internally motivated to acquire higher education, in Pakistan their percentage knowledge and learning becomes high in both, medicine and dentistry. ${ }^{31}$ In current study, female proportions are prominent in all 1st, 2nd, 3rd and 4th professional years of BDS where they make up a total of $n=62 / 85(72.9 \%)$. The results of current study agree with that of Amal SM who confirms the predominance of female participants. ${ }^{6}$ In his study results he reported that reflective learners present deep and organized learning approach and have better academic performance. However, in a study by Chalmers where more than half of the participants were females, $(57 \%$, 30/56) no difference in RLS score among genders was reported. ${ }^{15}$
On contrary, Sobral DT (a Brazilian researcher) investigated reflective level of 6th year medical students in 2000 and $2005 .{ }^{12,14}$ His established results demonstrate male predominance. During detecting Reflection-in-Learning Scale of clinically rotated medical students Sobral DT established no significant main effects for gender.

Previous studies conducted in Balochistan present low female literacy rate, however the current study reported contrasting result as majority of the study participants were females $(72.9 \%)$ from all 4 years of BDS. ${ }^{32,33}$ This change in gender distribution in Balochistan may be due to the awareness of literacy in women or it may be due to the lack of interest in male students towards learning and struggling hard. Additionally, Boenink reported that female participants presented exceptional reflective abilities which may be due to their personality frame of mind and high level of proficiency to execute reflective scrutiny which displays their creativity, talent and particular awareness. ${ }^{34}$ ChaunYuan reporterd 2:1 female to male ratio in his study, however he did not compare gender with reflective work. ${ }^{19}$

In addition, more contrasting results are reported. Chalmers $\mathrm{P}$ et al did not recognize any significant difference between male and females although there were $57 \%$ female participants in her study. ${ }^{15}$ Similarly, Phan HP reported no statistical significant gender difference in a survey involving 347 study participants where 151 were women. ${ }^{35}$

An Indian researcher, Devi V, observed female predominance in her study $(\mathrm{n}=78 / 153)$, whereas $55.2 \%$ participants of Heinerichs S's study $(\mathrm{n}=21 / 38)$ and $64.1 \%$ $(n=208 / 324)$ study contributors in the research of Tricio J were females. ${ }^{7,16,19}$ Kalk K reported 95\% female participants in Estonia ( $n=206 / 216)$. All these studies prove the women empowerment in education. ${ }^{16,21}$

\section{Age of Participants and RLS Score}

Participants of the current study were between the ages of 20-22 years. The results of current study are in accordance with the results of Chaun-Yuan study (20-22 years) and Chalmers $\mathrm{P}$ et al study (94\% between 20-29 years). ${ }^{19,15}$

Tricio $\mathrm{J}$ analyzed that students above the age of 22 years and those in high grades achieve higher reflective habits. ${ }^{7}$ This is reinforced by this study as students scoring higher in academics were above the age of 20-22 and they scored high in 14-item Reflection-in-Learning Scale. This finding may be due to the extra experience of senior students as a result of attending, facing and dealing with clinical scenarios and patients on daily basis. ${ }^{7}$

Heinerichs $\mathrm{S}$ reported that the mean age range of his study participants was $21.55 \pm 1.32$, whereas all the participants of Devi V's study were between the ages of 21-23. ${ }^{16,21}$ Mean age of the participants of Kalk K was 
$23.08 \pm 3.06 .4$ On the other hand, Sobral did not detect any difference of reflective abilities between ages of his study participants. ${ }^{14}$ The consequences of Sobral's research correlates with the outcomes of current study where no correlation was found between participant's age and reflective level. The RLS score of participants, above 23 years of age, was Mean \pm SD $82.36 \pm 3.85$. Senior participants show high scores of reflection-in-learning scale as compared to the junior ones $(<20$ years Mean \pm SD, $79.17 \pm 6.08)$. It may be due to the experience gained in clinical rotations, they have more options to discuss ill-defined situations, and can solve difficult cases along with P.Gs, senior doctors and faculty members.

\section{Strength of the study}

This study is the first of its kind to be conducted in Balochistan as well as in Pakistan. Despite of the problems students of Bolan Medical College are currently facing, they have exhibited the use of deep and organized learning strategies. Reflection-in-Learning Scale was appropriate for the assessment of the participants' reflective abilities. Educationists, in future, should work on reflection to improve student reflective abilities.

\section{Weaknesses of Current Study}

Present study addressed only one medical college through self-assessed questionnaire to measure reflective level. Strength of male students was low.

\section{CONCLUSION}

Females participants were more reflective, whereas age had no effect on RLS

\section{RECOMMENDATION}

To fill the gap of 1st and 2nd year student's reflective level and enhance their effective abilities, there should be discussions on reflection, and it should be introduced into the curriculum in early clerkship in the form of reflective journal writing, log books and/or group discussion. It may help students in making better informed decisions and clinical judgments, thus improving their future practice. In future, research should be carried out to evaluate the correlation between life performance of female students and RLS score.

\section{ACKNOWLEDGEMENT}

Authors offer regards and gratitude to all students of BDS, Bolan Medical College, Quetta for their willingness and voluntarily participation in research project.

\section{Disclaimer}

The abstract of this article is not presented or published in any conference, or published in an abstract book or any other relevant information.

\section{CONFLICT OF INTEREST}

Authors declare no conflict of interest. This project is not supported by any funding/grants.

\section{REFERENCES}

1. Marton F, Watkins D, Tang C. Discontinuities and continuities in the experience of learning: An interview study of high-school students in Hong Kong. Learn Instr. 1997; 7: 21-48. https://doi.org/10.1016/S0959-4752(96)00009-6

2. Samuelowicz KER\& DLP of OS: TS of a SLP of OS: TS of a S, Samuelowicz K. Higher Education Research \& Development Learning Problems of Overseas Students: Two Sides of a Story Learning Problems of Overseas Students?: Two Sides of a Story. High Education Res Dev. 2006; 6: 37-41.

3. Kember D, Leung DYP, Jones A, Loke AY, McKay J, Sinclair K, et al. Development of a Questionnaire to Measure the Level of Reflective Thinking. Assess Eval High Educ. 2000; 25(4): 381-95. https://doi.org/10.1080/713611442

4. Kalk K, Luik P, Taimalu M, Täht K. Validity and Reliability of Two Instruments to Measure Reflection: A Confirmatory Study. J Humanit Soc Sci. 2014; 18(2010): 121-34.

https://doi.org/10.3176/tr.2014.2.02

5. Zhang H. Who dominates the class, boys or girls? http://www.divaportal.org/smash/get/diva2:394795/fulltext01.pdf. 2010;

6. Amal M. The reflective process among undergraduate dental students?: the impact of age, gender, learning styles, learning approaches and the dental environment The Reflective Process among Undergraduate Dental Students?: the Impact of Age, Gender, Learning s. Jpostgr Med Thesis Queen Mary Univ London. 2010; 58(4): 270-4.

7. Tricio J, Woolford M, Escudier M. Dental students ' reflective habits: is there a relation with their academic achievements? Eur J Dent Educ. 2015; 19: 113-21.

https://doi.org/10.1111/eje.12111

8. Tagawa M. Physcian Self -Directed Learning. Kaohsiung J Med Sci; 2008; 24(7): 380-5.

https://doi.org/10.1016/S1607-551X(08)70136-0

9. Sobral DT. What kind of motivation drives medical students' learning quests? Med Educ. 2004; 38(9): 950-7. https://doi.org/10.1111/j.1365-2929.2004.01913.x

10. Hodges BD. Sea monsters \& whirlpools: Navigating between examination and reflection in medical education. Med Teach [Internet]. 
2015; 37(3): 261-6.

https://doi.org/10.3109/0142159X.2014.993601

11. Yusuff KB. Does self-reflection and peer-assessment improve Saudi pharmacy students ' academic performance and metacognitive skills? Saudi Pharm J [Internet]. King Saud University; 2015; 23(3): 266-75.

12. Sobral DT. An appraisal of medical students' reflection-in-learning. Med Educ. 2000; 34: 182-7.

https://doi.org/10.1046/j.1365-2923.2000.00473.x

13. Sobral DT. Medical students' reflection in learning in relation to approaches to study and academic achievement. Med Teach [Internet]. 2001; 23(5): 508-13.

https://doi.org/10.1080/01421590126488

14. Sobral DT. Medical students' mindset for reflective learning: A revalidation study of the reflection-in-learning scale. It has proved constructive validity and good

internal consistency. Adv Heal Sci Educ. 2005; 10(4): 303-14. https://doi.org/10.1007/s10459-005-8239-0

15. Chalmers P, Dunngalvin A, Shorten G. Reflective ability and moral reasoning in final year medical students: a semi-qualitative cohort study. Med Teach [Internet]. 2011; 33(5): e281-9.

https://doi.org/10.3109/0142159X.2011.558531

16. Devi V, Mandal T, Kodidela SVP. Integrating students' reflectionin-learning and examination performance as a method for providing educational feedback. J Postgr Med, Karnataka; 2012; 58(4): 270-4. https://doi.org/10.4103/0022-3859.105447

17. Kok J, Chabeli MM. Reflective journal writing: how it promotes reflective thinking in clinical nursing education: a students' perspective. Curationis. 2002; 25(3): 35-42.

https://doi.org/10.4102/curationis.v25i3.784

18. Kuiper RA, Pesut DJ. Promoting cognitive and metacognitive reflective reasoning skills in nursing practice: self-regulated learning theory. J Adv Nurs. 2004; 45: 381-91. https://doi.org/10.1046/j.1365-2648.2003.02921.x

19. Chuan-yuan C, Ying-tai W, Ming-hsia H, Jia-te L. Reflective learning in physical therapy students: Related factors and facilitative effects of a short introduction. Procedia-Soc Behav Sci [Internet]. Elsevier B.V.; 2013; 93: 1362-7.

20. Grant A, Kinnersley P, Field M. Dental students ' reflective habits: is there a relation with their academic achievements? BMC Res Notes. 2012; 5: 153.

https://doi.org/10.1186/1756-0500-5-153

21. Heinerichs S, Vela LI, Drouin JM. A Learner-Centered Technique and Clinical Reasoning, Reflection, and Case Presentation Attributes in Athletic Training Students. J Athl Train. 2013; 48(3): 362-71. https://doi.org/10.4085/1062-6050-48.2.17
22. Nuzhat A, Salem RO, Hamdan N Al, Ashour N. Gender differences in learning styles and academic performance of medical students in Saudi Arabia. Med Teach. 2013; 35(SUPPL. 1).

23. Van Nguyen H, Giang TT. Gender Difference in Academic Planning Activity among Medical Students. PLoS One. 2013; 8(2): e55845. https://doi.org/10.1371/journal.pone.0055845

24. Gulzar S, Lobo C, Shamim SM. Teaching experience and reflection. Pak J Med Sci 2009; 25(2): 338-41.

25. Khan JS, Biggs JSG, Tabasum S, Iqbal M. Assessment in Medical Education in Pakistan: Evaluation Evaluation. Biomedica 2012; 28 : 88-94.

26. Saeed MT. Students satisfaction with faculty instructions at Rehman Medical College, Peshawar K.P, Pakistan. JRMI; 2015; 1 (1): 9-16.

27. Peirce W. Designing Rubrics for Assessing Higher Order Thinking. 2007. p. http://academic.pg.cc.md.us/ wpeirce/MCCCTR/Design.

28. Hashmi AM, Rehman A, Butt Z, Aftab MA, Shahid A KS. Gender discrimination among medical students in Pakistan: A cross sectional survey. Pak J Med Sci. 2013; 29(2): 449-53.

https://doi.org/10.12669/pjms.292.3256

29. Franzen C. The Undergraduate Degree Project - Preparing Dental Students for Professional Work and Postgraduate Studies? 2014;1-19.

30. Jalal-ud-din M, Khan M. Socio-Economic and Cultural Constraints of Women in Pakistan with Special Reference to Mardan District, NWFP Province. Sarhad J Agric. 2008; 24(3): 485-93.

31. Maqsood S, Raza H. Getting Higher Education: Is it Really A Challenge for Females in Pakistan? Academic Research International 2012; 2(3): 352-60.

32. Magsi J, Khail M, Abdullah K. Literacy rate and education. http://balochistan.gov.pk/mics/MICS-4-Web/4-1-ResultsLiteracy\%20\&\%20Education.pdf. 2004; 29-42.

33. Salik M, Zhiyong Z. Gender Discrimination and Inequalities in Higher Education?: A Case Study of Rural Areas of Pakistan. Acad Res Int. 2014; 5(2): 269-76.

34. Boenink AD, Oderwald AK, De Jonge P, Van Tilburg W, Smal JA. Assessing student reflection in medical practice. The development of an observer-rated instrument: Reliability, validity and initial experiences. Med Educ. 2004; 38(4): 368-77.

https://doi.org/10.1046/j.1365-2923.2004.01787.x

35. Phan HP. Exploring students' reflective thinking practice, deep processing strategies, effort, and achievement goal orientations. Educational Psychology 2009; 29 (3): 297-313.

https://doi.org/10.1080/01443410902877988 


\section{ANNEXURE 1 REFLECTION-IN-LEARNING SCALE (RLS)}

Please answer the items below in relation to your learning experiences in dental programme. Draw a circle around the scale number closer to your usual behavior. To what extent have I: $[1=$ Never, $2=$ very rarely, $3=$ some times, $4=$ when possible, 5 often, $6=$ when required, $7=$ Always $]$

\begin{tabular}{|c|c|c|c|c|c|c|c|c|}
\hline \multirow[t]{2}{*}{$\begin{array}{l}\text { Q. } \\
\text { No }\end{array}$} & \multirow[t]{2}{*}{ Questions } & \multicolumn{7}{|c|}{$\begin{array}{l}\text { Usual behavior of BDS } \\
\text { students }\end{array}$} \\
\hline & & $\frac{\grave{d}}{\grave{\partial}}$ & $\begin{array}{l}\vec{d} \\
\ddot{i}\end{array}$ & 咅 & 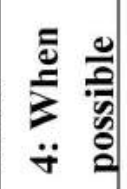 & $\stackrel{\bar{\varrho}}{\ddot{0}}$ & 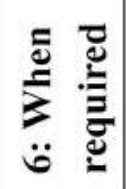 & $\begin{array}{l}\sum_{i}^{n} \\
\stackrel{i}{r} \\
\ddot{r}\end{array}$ \\
\hline 1 & $\begin{array}{l}\text { Carefully planned my learning tasks in the courses and } \\
\text { training activities of medical programme }\end{array}$ & & & & & & & \\
\hline 2 & $\begin{array}{l}\text { Talked with my colleagues about learning and methods } \\
\text { of study }\end{array}$ & & & & & & & \\
\hline 3 & Reviewed previously studied subjects during each time & & & & & & & \\
\hline 4 & $\begin{array}{l}\text { Integrated all topics in a course with each other and } \\
\text { with those of other courses and training activities }\end{array}$ & & & & & & & \\
\hline 5 & $\begin{array}{l}\text { Mentally processed what I already knew and what I } \\
\text { needed to know about the topics or procedures }\end{array}$ & & & & & & & \\
\hline 6 & $\begin{array}{l}\text { Been aware of what I was learning and for what } \\
\text { purposes }\end{array}$ & & & & & & & \\
\hline 7 & $\begin{array}{l}\text { Sought out interrelations between topics in order to } \\
\text { construct more comprehensive notions about some } \\
\text { theme }\end{array}$ & & & & & & & \\
\hline 8 & $\begin{array}{l}\text { Pondered over the meaning of the things I was } \\
\text { studying and learning in relation } t \text { my personal } \\
\text { experience }\end{array}$ & & & & & & & \\
\hline 9 & $\begin{array}{l}\text { Conscientiously sought to adapt myself to the varied } \\
\text { demands of the different courses and training activities }\end{array}$ & & & & & & & \\
\hline 10 & $\begin{array}{l}\text { Systematically reflected on how I was studying and } \\
\text { learning in different contexts and circumstances }\end{array}$ & & & & & & & \\
\hline 11 & $\begin{array}{l}\text { Mindfully summarized what I was learning day in, day } \\
\text { out, in my studies }\end{array}$ & & & & & & & \\
\hline 12 & $\begin{array}{l}\text { Exerted my capacity to reflect during learning } \\
\text { experience }\end{array}$ & & & & & & & \\
\hline 13 & $\begin{array}{l}\text { Diligently removed negative feelings in relations to } \\
\text { aims, objectives, behaviors, topics or problems } \\
\text { pertaining to my studies. }\end{array}$ & & & & & & & \\
\hline 14 & Constructively self-assessed my work as a learner & & & & & & & \\
\hline
\end{tabular}

